\title{
Interactions between Nitric Oxide and Corticosterone in the Regulation of Progenitor Cell Proliferation in the Dentate Gyrus of the Adult Rat
}

\author{
Scarlett B Pinnock', Rubika Balendra', Melanie Chan', Lauvence T Hunt', Tabitha Turner-Stokes' and \\ Joe Herbert*, \\ 'Department of Physiology, Development and Neuroscience and Cambridge Centre for Brain Repair, University of Cambridge, Cambridge, UK
}

It is well established that L-NAME, a generic NOS inhibitor, stimulates neurogenesis in the dentate gyrus of the adult rat and corticosterone reduces it. These experiments explore the interaction between L-NAME and corticosterone. L-NAME (50 mg/kg), as expected, increased proliferation, but also lowered plasma corticosterone levels. However, the stimulating action of L-NAME depends on the presence of rhythmic changes in plasma corticosterone, as it is abolished in rats treated with a subcutaneous implant of corticosterone, which flattens the diurnal rhythm. Adrenalectomized rats implanted with corticosterone also failed to respond to L-NAME. Giving them a single daily injection of corticosterone $(2 \mathrm{mg} / \mathrm{kg})$ in an attempt to replicate the diurnal rhythm restored the sensitivity of the progenitor cells to L-NAME. The mechanism for this result remains to be investigated. Excess corticosterone given by daily injection $(40 / \mathrm{mg} / \mathrm{kg}$ ) reduced proliferation but did not alter the response to L-NAME, even though this occurred from a lower baseline. nNOS was demonstrable only in the inner (proliferative) layer of the dentate gyrus in control rats, and did not alter following excess corticosterone treatment. iNOS was detectable at low levels in control rats, but was increased markedly following corticosterone. eNOS was evident throughout the dentate gyrus, and also increased after corticosterone (particularly in the hilus). Aminoguanidine ( $100 \mathrm{mg} / \mathrm{kg} /$ day; an iNOS antagonist) significantly increased proliferation in corticosterone-treated rats (40 mg/kg/day) but not in controls without additional corticosterone, confirming that iNOS plays a role in corticosterone-regulated neurogenesis. Corticosterone may thus act on progenitor cells in part at least through increased nitric oxide (NO) formation. The effects of reduced $\mathrm{NO}$ on neurogenesis may rely on a dual mechanism: corresponding reductions in plasma corticosterone and increased induction of iNOS (and/or eNOS) within the dentate gyrus. The possibility that $\mathrm{NO}$ acts downstream of glucocorticoids in the dentate gyrus is suggested. Neuropsychopharmacology (2007) 32, 493-504. doi:I 0. I038/sj.npp. I 30 I245; published online I November 2006

Keywords: nitric oxide; corticosterone; neurogenesis; proliferation; hippocampus; dentate gyrus

\section{INTRODUCTION}

The persistence of neurogenesis in the dentate gyrus of the hippocampus into adulthood has radically altered our view of this part of the brain (Altman and Das, 1965). The dentate gyrus of the adult rat (which contain c. $0.5-1 \mathrm{M}$ neurons) makes about 5000-8000 new neurons per day (Christie and Cameron, 2006) and these are integrated into the normal circuitry (Hastings and Gould, 1999). However, this remarkable process has another equally remarkable property: it is highly variable (Mirescu and Gould, 2006).

\footnotetext{
*Correspondence: Professor J Herbert, Department of Physiology, Development and Neuroscience, University of Cambridge, Downing Street, Cambridge CB2 3 DY, UK, Tel: + 441223 333749, Fax: + 44 I 223 333786, E-mail: jh24@cam.ac.uk

Received 22 May 2006; revised 30 August 2006; accepted 5 September 2006

Online publication: 26 September 2006 at http://www.acnp.org/ citations/Npp092606060338/default.pdf
}

Much of this lability is a consequence of the extreme sensitivity of progenitor cell proliferation to adrenal corticoids, as the latter themselves are so labile (Cameron and Gould, 1994). Glucocorticoids show a marked, but variable, diurnal rhythm, and are moderated by stress as well as genetic factors, age, and 'programming' of adrenal function by early adversity (Dallman et al, 2004; Fish et al, 2004; Meaney et al, 1996; Mirescu et al, 2004; Sapolsky et al, 1987; Weaver et al, 2000).

Giving excess corticosterone (or stressing the animal) suppresses progenitor cell proliferation (Cameron and Gould, 1994; Mirescu and Gould, 2006). We have shown that glucocorticoids also control survival and differentiation of progenitor cells (Wong and Herbert, 2004, 2006). Adrenalectomy increases the subsequent survival of progenitors pre-labelled with 5-bromo-2 deoxyuridine (BrdU) at 28 days, whereas excess corticosterone decreases survival. The survival of newly formed neurons are sensitive to this steroid for the first 18 days only (Wong and Herbert, 2004). 
Corticosterone also diminished the acquisition of a neuronal phenotype, but the effect occurs from around 19 to 27 days after the cells were born (Wong and Herbert, 2006). The overall result is that raised corticosterone suppresses neuronal production, whereas adrenalectomy increases the number of new neurons in the adult hippocampus.

Nitric oxide (NO) also regulates neurogenesis. Inhibiting NO synthase(s) with L-NAME stimulates proliferation (Packer et al, 2003; Park, 2003). The SVZ is surrounded by differentiated neurons expressing nNOS which is also present in neuronal precursors in the dentate gyrus (Islam et al, 2003; Moreno-Lopez et al, 2004). There are three isoforms of NOS (nNOS, iNOS, eNOS) (Cardenas et al, 2005), although whether one or more are concerned in the process of neurogenesis than others is still not clear. A major question, therefore, is how glucocorticoids and NO interact. In particular, do they act on separate or common mechanisms in the dentate gyrus, and if the latter is the case, is NO 'downstream' of the action of glucocorticoids? Or does L-NAME exert its action on proliferation secondarily through an effect on circulating glucocorticoids? These are the questions we address in this paper.

\section{MATERIALS AND METHODS}

\section{Animals}

All procedures were carried out under Home Office (UK) licence. Male Lister-Hooded rats (Harlan, Oxon, UK) were used; they weighed around $200-250 \mathrm{~g}$ at the start of the experiment. Rats were housed in groups of three per cage in a controlled environment. Ambient temperature was maintained at $21^{\circ} \mathrm{C}$ and humidity at $55 \%$ with ad libitum access to food and tap water (and $0.9 \%$ saline for adrenalectomized animals). Animals were kept on reversed 12-h light: 12-h dark cycles (lights off at 1000 hours).

Corticosterone was administered as $30 \%$ pellets in cholesterol subcutaneously (s.c.) (controls received cholesterol alone). Bilateral adrenalectomy was carried out using a dorsal approach under halothane $/ \mathrm{N}_{2} \mathrm{O}$ anesthesia. Adrenalectomized animals were also implanted with a single $30 \%$ corticosterone pellet s.c. In all experiments, the blood samples were collected by cardiac puncture in heparinized tubes within $3 \mathrm{~min}$ of injecting a terminal dose of pentobarbitone sodium, centrifuged and stored at $-20^{\circ} \mathrm{C}$ until assayed to measure plasma corticosterone concentrations. The rats' brains were collected, frozen immediately on dry ice, and then stored at $-70^{\circ} \mathrm{C}$ until required.

\section{Experimental Groups}

Experiment 1. The effect of giving both $L-N A M E$ and phasic corticosterone (40 $\mathrm{mg} / \mathrm{kg} /$ day by daily injection). Four groups of intact rats $(n=6)$ were used. They were treated for 7 days as follows: (i) $0.9 \%$ saline + sesame oil, (ii) L-NAME $50 \mathrm{mg} / \mathrm{kg}$ (dissolved in $0.9 \%$ saline) intraperitoneally (i.p.) daily + sesame oil, (iii) corticosterone $40 \mathrm{mg} / \mathrm{kg} /$ day s.c. in sesame oil + saline, and (iv) L-NAME + corticosterone. On day 7 , they received one injection of BrdU ( $200 \mathrm{mg} / \mathrm{kg}$ i.p.) and were killed $24 \mathrm{~h}$ later at 1000 hours. Sections were examined for (i) Ki-67, a nuclear protein expressed in all phases of the cell cycle except the resting phase (Kee et al, 2002) and BrdU, a thymidine analog (immunohistochemistry (IHC)), (ii) nNOS, iNOS (IHC and in situ), and eNOS (IHC), and (iii) GR (glucocorticoid receptor) and MR (mineralocorticoid receptor) (in situ).

Experiment 2. Diurnal changes in proliferation rates and the effects of $L-N A M E$ in rats implanted with a $30 \%$ pellet of corticosterone. Four groups of intact rats were used $(n=6)$. Half of the animals were implanted s.c. with $30 \%$ corticosterone pellet and the other half with cholesterol. After 1 day, half of each group received either a daily injection of $50 \mathrm{mg} / \mathrm{kg} \mathrm{L-NAME}$ (dissolved in $0.9 \%$ saline) or a control injection (saline) for a further 7 days. All animals were killed at two time points (1000 or 1600 hours) by an overdose of pentobarbitone sodium, as described above. Sections were examined for (i) Ki-67, (ii) nNOS (IHC and in situ), and (iii) iNOS (IHC and in situ).

Experiment 3. Effects of $L-N A M E$ in ADX rats implanted with a 30\% corticosterone pellet. This experiment tested whether increasing the level of corticosterone would restore the response to L-NAME in corticosterone 'clamped' ADX rats.

Twenty-four rats were adrenalectomized and implanted s.c. with $30 \%$ corticosterone pellets. The next day half of the animals received a daily injection of corticosterone s.c. $(2 \mathrm{mg} / \mathrm{kg})$ or sesame oil in the beginning of the dark phase (1000 hours) for 12 days ( $n=6 /$ group). After 5 days, half of each group received either a daily injection of $50 \mathrm{mg} / \mathrm{kg}$ L-NAME (dissolved in $0.9 \%$ saline) or a control injection (saline) for a further 7 days. Sections were stained for (i) Ki-67, (ii) nNOS (in situ), and (iii) iNOS (in situ).

Experiment 4. Effect of aminoguanidine in corticosteronetreated rats. This experiment explored the effect of the selective iNOS antagonist aminoguanidine on the proliferation of progenitor cells in both control and corticosteronetreated rats. Two groups of 10 rats received either daily injections of sesame oil (7 days) or corticosterone ( $40 \mathrm{mg} /$ $\mathrm{kg}$ ). Half of each group also received either i.p. saline or aminoguanidine dissolved in saline $(100 \mathrm{mg} / \mathrm{kg} /$ day for 7 days). Sections were stained for Ki-67 as above.

\section{Brain Sections}

Frozen, coronal brain sections, $20 \mu \mathrm{m}$-thick, were mounted onto polylysine-coated slides and stored at $-70^{\circ} \mathrm{C}$ until processed for in situ hybridization (ISH) or IHC. For each brain, frozen coronal sections were taken from the entire length of the dorsal hippocampus and mounted on a polylysine microscopic slides (BDH, Leicestershire, UK) stored in $-70^{\circ} \mathrm{C}$ until required. Several series of sections, each one in 10 of those cut, were taken. All measurements were made on 12 sections for Ki-67 and BrdU, and three sections for ISH (see below for further details).

\section{Corticosterone Assay}

Plasma corticosterone concentrations were measured by radioimmunoassay according to a validated procedure 
described previously (Chen and Herbert, 1995). The intraassay coefficients of variation were: intra-assay, $5.07 \%$ for experiment $1,6.16 \%$ for experiment 2, and $5.55 \%$ for experiment 3. The sensitivity of the assay was $0.98 \mathrm{ng} / \mathrm{ml}$.

\section{Immunohistochemistry}

Sections for all the immunostaining were first fixed for $5 \mathrm{~min}$ in $4 \%$ paraformaldehyde ( $\mathrm{pH} \mathrm{7.4,} \mathrm{Fisher,} \mathrm{Lough-}$ borough, UK) then rinsed twice with KPBS. For BrdU immunolabelling, the sections were incubated with $0.01 \mathrm{M}$ citric acid for $5 \mathrm{~min}$ at $98^{\circ} \mathrm{C}$, rinsed and incubated in $3 \%$ $\mathrm{H}_{2} \mathrm{O}_{2}$ for $10 \mathrm{~min}$, rinsed, digested with trypsin $(0.025 \%)$ in $\mathrm{dd}_{2} \mathrm{O}$, rinsed, denatured in $2 \mathrm{~N} \mathrm{HCl}$ at $37^{\circ} \mathrm{C}$ for $30 \mathrm{~min}$, rinsed and incubated overnight in KPBS containing $1 \%$ normal horse serum, $0.5 \%$ triton and mouse monoclonal antibody against BrdU (1:200, Novocastra, Newcastle upon Tyne, UK). On the next day, the sections were rinsed twice, incubated for $1 \mathrm{~h}$ with $0.5 \%$ biotinylated secondary mouse IgG antibody (Vectastain Elite ABC kit, Vector laboratories, Peterborough, UK) diluted in KBPS containing 1.0\% normal horse serum and $0.3 \%$ triton. The sections were then rinsed, incubated in avidin-biotin-horseradish peroxidase complexes (1:50, ABC kit, Vector laboratories, UK) for $1 \mathrm{~h}$, rinsed again, followed by diaminobenzidine reaction. They were then dehydrated by passing through graded alcohols and incubated in Histoclear overnight, and coverslipped under DPX for light microscopic analysis.

For Ki-67 IHC, sections were incubated in $0.01 \mathrm{M}$ citric acid for $40 \mathrm{~min}$ at $98^{\circ} \mathrm{C}$, rinsed and incubated overnight in KPBS containing $1 \%$ normal horse serum, $0.5 \%$ triton and mouse monoclonal antibody against Ki-67 (1:100, Novocastra). The sections were incubated with biotinylated secondary mouse IgG antibody and visualized with avidinbiotin-peroxidase complex, followed by diaminobenzidine reaction, dehydrated and coverslipped as above. For BrdU and nNOS or iNOS double labelling, immunofluorescence sections were incubated with rabbit anti nNOS or rabbit anti-iNOS (Zymed laboratories, 1:200 in 0.4\% Triton with normal goat serum) overnight at room temperature. eNOS single labelling (Zymed laboratories, 1:200) was carried similarly. Next day, sections were rinsed, incubated for $1 \mathrm{~h}$ with $0.5 \%$ biotinylated secondary rabbit IgG antibody (Vectastain Elite ABC kit), rinsed and incubated for $30 \mathrm{~min}$ in Alexa streptavidin 568 (Molecular probes, 1:200); then, sections were rinsed and denatured with $2 \mathrm{~N}$ $\mathrm{HCl}$ at $37^{\circ} \mathrm{C}$ for $30 \mathrm{~min}$, rinsed and incubated with mouse anti-BrdU (1:200, Novocastra) in $0.4 \%$ Triton with normal goat serum overnight at $37^{\circ} \mathrm{C}$. The following day the sections were rinsed and incubated at room temperature with Alexa 488 (Molecular probes, 1:500) for $30 \mathrm{~min}$ after several washes, the sections were coverslipped with mounting medium (Vector).

\section{In Situ Hybridization}

Brains were sectioned at $20 \mu \mathrm{M}$ at $-20^{\circ} \mathrm{C}$ onto polylysinecoated microscopic slides (Sigma, Dorset, UK). Sections were allowed to air dry at room temperature and were then fixed with $4 \%$ paraformaldehyde (Sigma) for $5 \mathrm{~min}$, washed in PBS and then dehydrated in 70\% ethanol and $95 \%$ ethanol for $5 \mathrm{~min}$ before finally storing in fresh $95 \%$ ethanol.
ISH was carried out under RNAase-free conditions. The accuracy of synthetic antisense oligonucleotide probes was confirmed by BLAST searches on NCBI.A 45 base and a 30 base oligonucleotide complementary to exonic mRNA encoding the nNOS and iNOS enzyme (Mineta et al, 2004) $5^{\prime}$-gcc ttg ggc atg ctg agg gcc att acc cag acc tgt gac tct gtc- $3^{\prime}$ (Kwak et al, 2005) and iNOS $5^{\prime}$-ctg cac cca aac acc aag gt- $3^{\prime}$ as well as a 33 base and 39 base oligonucleotide complementary to exonic mRNA encoding rat GR and MR sequence was also used (McQuade et al, 2004; van Riel et al, 2003). $5^{\prime}$-agg aga atc ctc tgc tgc ttg gaa tct gcc tga- $3^{\prime}$ and $5^{\prime}$-ttc gga ata gca ccg gaa acg cag ctg acg ttg aca atc t-3'.

All probes were end-labelled with ${ }^{35}$ S-ATP as follows: $2 \mu \mathrm{l}$ of purified oligonucleotide $(5 \mathrm{ng} / \mu \mathrm{l})$ was added to $1.25 \mu \mathrm{l}$ buffer and $1.25 \mu \mathrm{l}$ cobalt chloride (Biosystem, New England, UK). DEPC-treated water $(6.5 \mu \mathrm{l})$ was added, followed by $1 \mu$ terminal ${ }^{35} \mathrm{~S}$ deoxyadenosine $5^{\prime}$ ( $\alpha$-thio) triphosphate $(10 \mathrm{mCi} / \mathrm{ml})$ (Amersham, Buckinghamshire, UK) and $0.5 \mu \mathrm{l}$ (15-20 U) terminal deoxynucleotide transferase enzyme (Biosystem). Probes were incubated at $37^{\circ} \mathrm{C}$ for $1 \mathrm{~h}$ before $40 \mu \mathrm{l}$ of DEPC water was added to terminate the reaction. Purification of labelled probe from unincorporated nucleotides was accomplished by centrifugation (3000 r.p.m. for $2 \mathrm{~min}$ ) through a G-50 sephadex micro-column (Amersham). Probes were evaluated for incorporation of radiolabel by scintillation counting. All hybridizations were carried out at $2500-5000$ c.p.m./ $\mu$ in hybridization buffer (50\% deionized formamide, $4 \times$ SSC, $5 \times$ Denhardt's, $100 \mu \mathrm{g} / \mathrm{ml}$ polyadenylic (potassium salt) acid, $200 \mu \mathrm{g} / \mathrm{ml}$ salmon sperm DNA, $120 \mu \mathrm{g} / \mathrm{ml}$ heparin (BDH), $25 \mathrm{mM}$ sodium phosphate ( $\mathrm{pH} 7.0), 1 \mathrm{mM}$ sodium pyrophosphate, $10 \%(\mathrm{w} / \mathrm{v})$ dextran sulfate in DEPC-treated water (all Sigma). Sections were covered with parafilm and hybridized overnight at $44^{\circ} \mathrm{C}$ in a humid atmosphere. Excess unbound probe was removed using the following washes: slides were rinsed in $1 \times$ SSC (saline sodium citrate, Sigma) at room temperature, washed twice for $30 \mathrm{~min}$ at $55^{\circ} \mathrm{C}$ with $1 \times \mathrm{SSC}$ and then rinsed at room temperature for $2 \mathrm{~min}$, each in $1 \times$ SSC, $0.1 \times$ SSC, $18 \Omega$ water, 50,70 , and $95 \%$ ethanol $(\mathrm{BDH})$. Sections were thoroughly air-dried at room temperature before exposure to autoradiographic X-ray film (Amersham) for 10 days for iNOS, and nNOS and 5 days each for GR and MR. Sense probes for each of the mRNAs were run as negative controls.

\section{Quantification}

Proliferating cells. All slides were randomized and coded before quantitative analysis. Sections were examined using a $40 \times$ objective, and BrdU-labelled and Ki-67-stained cells were counted

Only cells on the border of the subgranular zone were counted. The data shown are the mean total count obtained from 12 sections per animal.

$m R N A$ expression. For quantification of mRNA, the sections and $\mathrm{C}^{14}$-labelled standards of known radioactivity (Amersham) were placed in X-ray cassettes and then exposed to autoradiographic film. The optical density (OD) of the autoradiographic images was measured using a computerized PC-based image analysis system (Scion). Image OD's were obtained in three/four consecutive 
sections per rat and the mean value for each rat was used to calculate group means. Sections from all groups were hybridized at the same time to avoid intrinsic variations between different ISHs.

Statistics. Grouped data were analyzed by two-way ANOVA or Student's $t$-test, both with logarithmic transformation if the variances were not homogenous. In some experiments, procedures on subgroups were carried out at different times: in these cases, within-subgroup comparisons were made using $t$-tests or one-way ANOVAs.

\section{RESULTS}

Experiment 1. The Effect of Giving Both L-NAME and Phasic Corticosterone ( $40 \mathrm{mg} / \mathrm{kg} /$ day by Daily Injection)

Proliferation. Overall, there was a close correlation between the numbers of Ki-67 and BrdU-labelled cells in the dentate gyrus (Spearman $\rho=0.93, p<0.001$ ) (Figure 1). As expected, corticosterone $(40 \mathrm{mg} / \mathrm{kg} / \mathrm{day}$ as a single injection) reduced the number of both $\mathrm{Ki}-67$ and BrdU-stained (proliferating) cells in the inner layer of the dentate gyrus (two-way ANOVA: $\mathrm{F}=22.9, p<0.001$ ). L-NAME, also as expected, significantly increased the number of labelled cells $(F=63.7, p<0.001)$. However, there was no interaction between corticosterone and L-NAME treatments on either Ki-67 expression or BrdU labelling $(\mathrm{F}=0.001, p$ : NS). Figure 2 shows that the addition of L-NAME stimulated the number of proliferating cells in both groups, albeit from a lower baseline in the corticosterone-treated ones. Table 1 shows that L-NAME also reduced plasma corticosterone significantly $(\mathrm{F}=13.8, p<0.004)$ in rats not treated with additional steroid.

$n N O S$, iNOS, and eNOS. In control rats, nNOS was expressed unevenly in the hippocampus. Levels were comparatively high in the CA2, CA3 and the dentate gyrus, but absent in CA1 (Figure 3). Both nNOS and iNOS were restricted to cells lying along, or adjacent to, the innermost layer of the dentate gyrus (ie, the progenerative layer). iNOS protein and mRNA were expressed very weakly in the dentate gyrus in control animals, and were essentially absent in the other areas. Corticosterone markedly in- creased the expression of iNOS mRNA in the dentate gyrus $(t=3.6, p<0.007)$ while having no effect on nNOS $(t=0.43$, $p$ : NS) (Figure 3 ). eNOS protein, in contrast to the other isoforms, was expressed throughout the dentate gyrus. Corticosterone increased eNOS (qualitatively), particularly in the hilus of the dentate gyrus (Figure 4).

Fluorescent sections stained for both BrdU and nNOS showed no co-localization in the subgranular zone of the dentate gyrus but cells positive for either were found in close proximity (Figure 4). iNOS in corticosterone-treated rats BrdU was present in too few cells to examine colocalization fully. However, whereas there were a number of cells expressing one or the other, we were only able to find two cells that expressed both iNOS and BrdU (Figure 4).

$G R$ and $M R$. There were marked regional differences in the expression of GR within the hippocampus in control animals (Figure 5). Expression was highest in the dentate gyrus, intermediate in CA1 and 2, but almost absent in CA3 (Figure 5). MR was also highest in the dentate, but showed intermediate levels in CA1, 2, and 3 (which were essentially

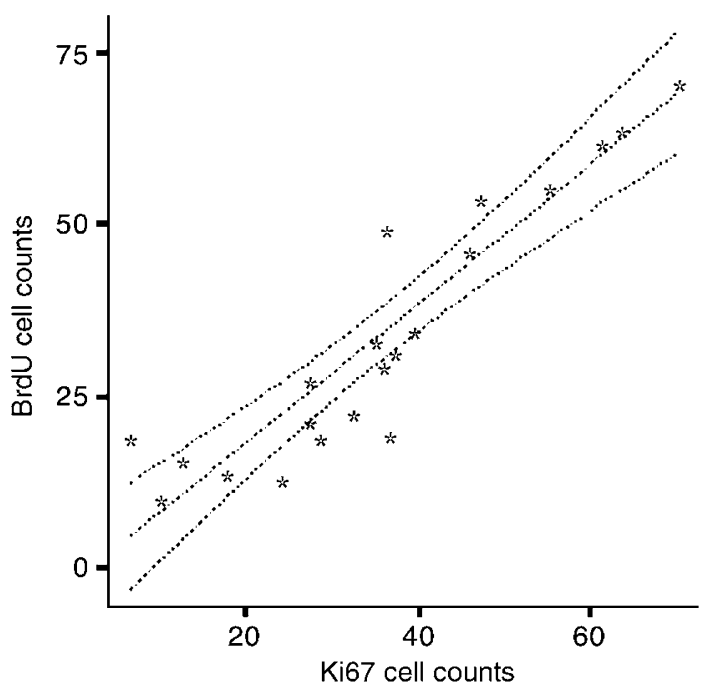

Figure I Correlation between Ki67 and BrdU cell counts in individual rats in experiment I. Spearman $\rho=0.8 \mathrm{I}, p=0.00 \mathrm{I}$. Linear regression equation: $\mathrm{BrdU}=-2.26+1.02 * \mathrm{Ki}-67$.
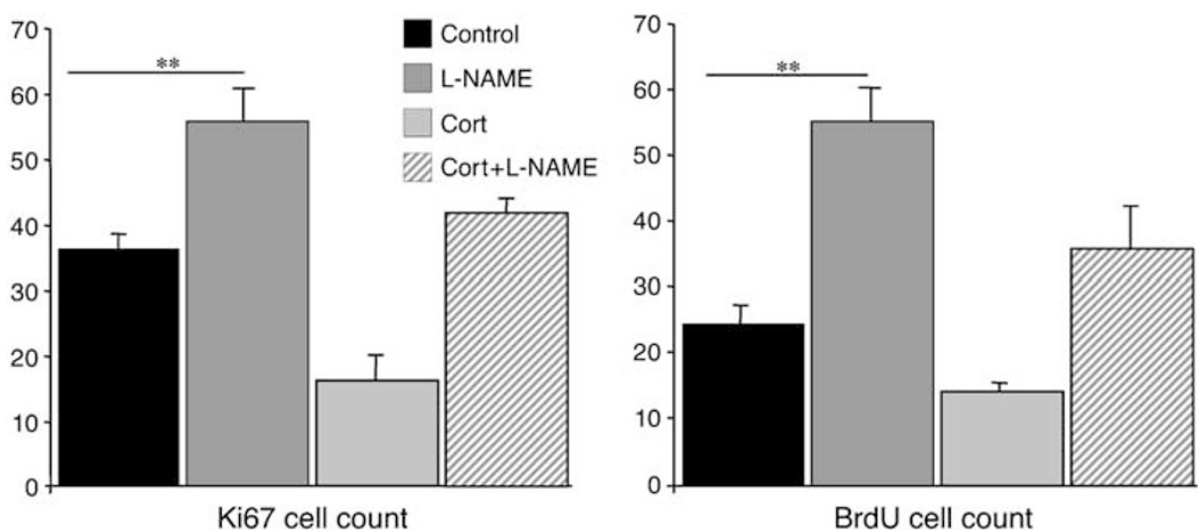

BrdU cell count

Figure 2 Ki-67-labelled cells and BrdU in the dentate gyrus after treatment with either L-NAME (50 mg/kg/day), or daily corticosterone injection $(40 \mathrm{mg} / \mathrm{kg})$ for 7 days or both. BrdU $(200 \mathrm{mg} / \mathrm{kg})$ was given $24 \mathrm{~h}$ before killing. Values: means \pm SEM. $* * * 0.001$. 
similar (Figure 5)). Treatment with L-NAME increased the expression of $\mathrm{GR}(\mathrm{F}=9.3, p<0.04)$ but not $\mathrm{MR}(\mathrm{F}=3.4$, $p$ : NS) in the dentate gyrus (Figure 5).

Table I Mean ( \pm SEM) Plasma Corticosterone Levels in the Three Experiments

\begin{tabular}{llcc}
\hline & Adrenal & $\begin{array}{l}\text { Plasma } \\
\text { corticosterone }\end{array}$ & F-value \\
\hline $\begin{array}{c}\text { Experiment I } \\
\text { Control }\end{array}$ & Intact & $204.5 \pm 24.3$ & 13.8*** \\
L-NAME & & $91.8 \pm 18.1$ & \\
& & & \\
Experiment 2 & Intact & $188.3 \pm 30.0$ & L-NAME: 0.4 \\
Control: AM & & $200.3 \pm 8.7$ & AMPM I2.6** \\
L-NAME: AM & & $140.3 \pm 25.7$ & \\
Control: PM & & $101.3 \pm 8.9$ & \\
L-NAME: PM & & & \\
& & & \\
Experiment 3 & ADX+30\% cort pellet & $216.6 \pm 27.7$ & 20.6** \\
Control & & $73.4 \pm 15.1$ & \\
L-NAME & & & \\
\hline
\end{tabular}

*** $p<0.01$
Experiment 2. Diurnal Changes in Proliferation Rates and the Effects of L-NAME in Intact Rats and those Implanted with a $30 \%$ Pellet of Corticosterone

Proliferation. There was a marked diurnal rhythm in the number of Ki-67-labelled cells in the dentate gyrus of intact in control (intact, cholesterol-implanted) rats. Levels at 1600 hours were significantly higher than those at 1000 hours. However, this was not observed in rats that had received a s.c. pellet of corticosterone. This treatment flattened the diurnal change in plasma corticosterone, which was observed in the control (cholesterol-implanted) intact rats (Figure 6). A two-way ANOVA within the cholesterol group (time of day, L-NAME) showed that both factors had first order significant effects on the number of Ki-67-labelled cells in cholesterol-implanted rats (time of day, $\mathrm{F}=17.1, p<0.001$; L-NAME, $\mathrm{F}=13.9, p<0.006$ ). However, in the corticosterone-implanted group, there were no significant effects of either time of day or L-NAME treatment $(\mathrm{F}=1.2$ and $0.03, p: \mathrm{NS})$.

In this experiment, L-NAME had no effect on plasma corticosterone in rats not given additional steroid $(\mathrm{F}=0.42, p: \mathrm{NS})$, although there was a highly significant time of day effect both in control and L-NAME-treated groups. $(\mathrm{F}=12.6, \quad p<0.008)$ (Table 1 and Figure 6). Implanting a $30 \%$ corticosterone pellet abolished the time

a

nNOS
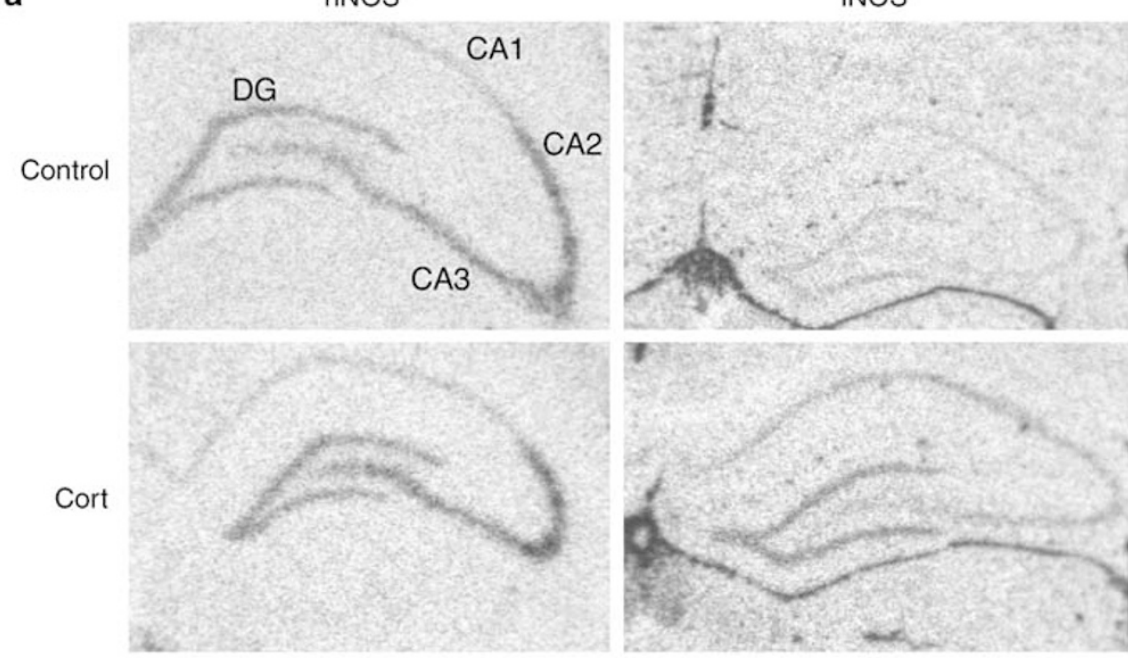

b

C

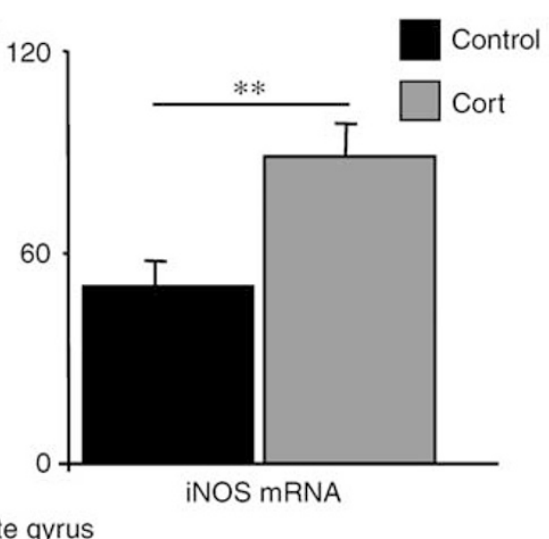

Dentate gyrus

Figure 3 (a) Sections through the dentate gyrus shows the expression of nNOS and iNOS mRNA. The effect of chronic treatment with corticosterone $(40 \mathrm{mg} / \mathrm{kg} / \mathrm{day})$ for 7 days on (b) nNOS and (c) iNOS mRNA in the dentate gyrus. Values: means \pm SEM. $* * * 0.001$. 

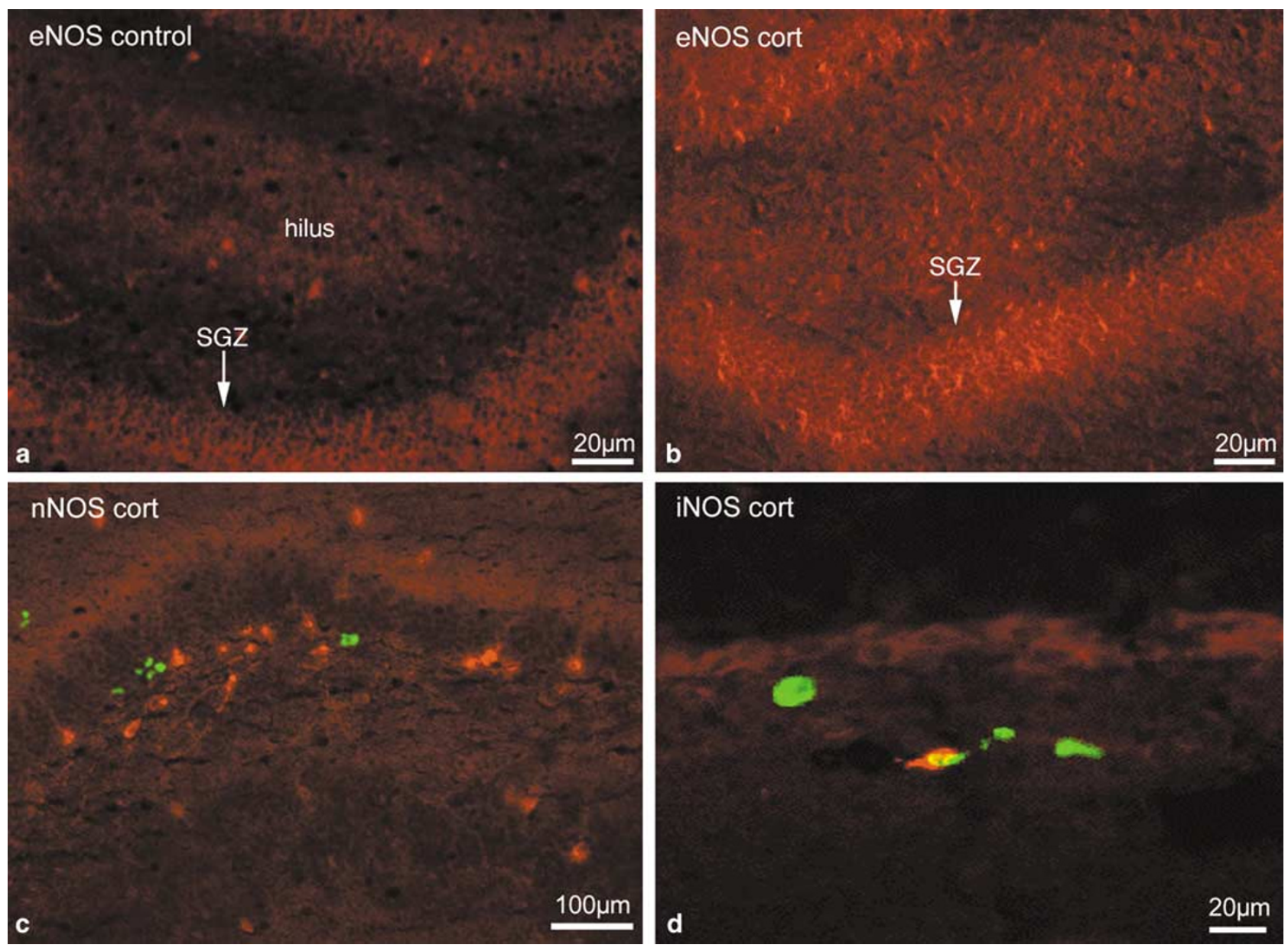

Figure $4 \mathrm{HC}$ staining in the dentate gyrus for (a) eNOS in controls, (b) eNOS following 7 days corticosterone treatment, (c) no co-localization of nNOS (red) and BrdU (green), and (d) limited co-localization of iNOS (red) and BrdU (green).

of day effect on plasma corticosterone $(\mathrm{F}=2.1, p$ : NS) (Figure 6).

nNOS and iNOS. There were no differences in the level of iNOS expression between the four groups. A two-way ANOVA confirmed that neither flattening the corticosterone rhythm $(\mathrm{F}=1.8, p=0.2)$ nor treatment with L-NAME $(\mathrm{F}=0.2, p=0.6)$ had a significant effect on the expression of iNOS. There was no interaction between corticosterone and L-NAME $(\mathrm{F}=1.2, p=0.3)$ (data not shown). Levels of nNOS mRNA were also not different between the groups. As in the previous experiment, fluorescent sections stained immunocytochemically for both Ki-67 and nNOS showed no co-localization in the subgranular zone of the dentate gyrus but cells positive for either were found in close proximity. nNOS cells were also found in the hilus (data not shown). We did not explore the phenotype of NOSexpressing cells further in this study (eg by double-staining with NeuN, GFAP, etc).

\section{Experiment 3. Effects of L-NAME in ADX Rats Implanted with a $30 \%$ Corticosterone Pellet}

Proliferation. There was no effect of L-NAME on proliferation rates (Ki-67) in ADX corticosterone-implanted rats $(\mathrm{F}=2.9, p$ : NS). Adding a single daily injection of corticosterone $(2 \mathrm{mg} / \mathrm{kg} /$ day $)$ resulted in significantly increased proliferation after L-NAME compared to control (daily corticosterone + saline) (Figure 7) (two-way ANOVA: corticosterone injection, $\mathrm{F}=5.5, p=0.03$ ). L-NAME significantly reduced plasma corticosterone in ADX rats implanted with a $30 \%$ corticosterone pellet (Table 1 ).

$n N O S$ and $i N O S$. There was hardly any expression of iNOS in the dentate gyrus of adrenalectomized rats implanted with $30 \%$ corticosterone pellets. Adding a daily injection of corticosterone $(2 \mathrm{mg} / \mathrm{kg})$ had no effect on the expression of iNOS. There was no change in nNOS mRNA expression in any of the groups.

\section{Experiment 4. Effect of Aminoguanidine}

Aminoguanidine had no effect on proliferation in oilinjected intact rats. Corticosterone reduced $\mathrm{Ki}-67$-stained cells $(\mathrm{F}=27.8, p<0.001)$; in these corticosterone-treated animals, aminoguanidine increased proliferation by $38.6 \%$ $(p<0.03)$ (Figure 8). Aminoguanidine had no effect on plasma corticosterone (data not shown). 
a GR MR
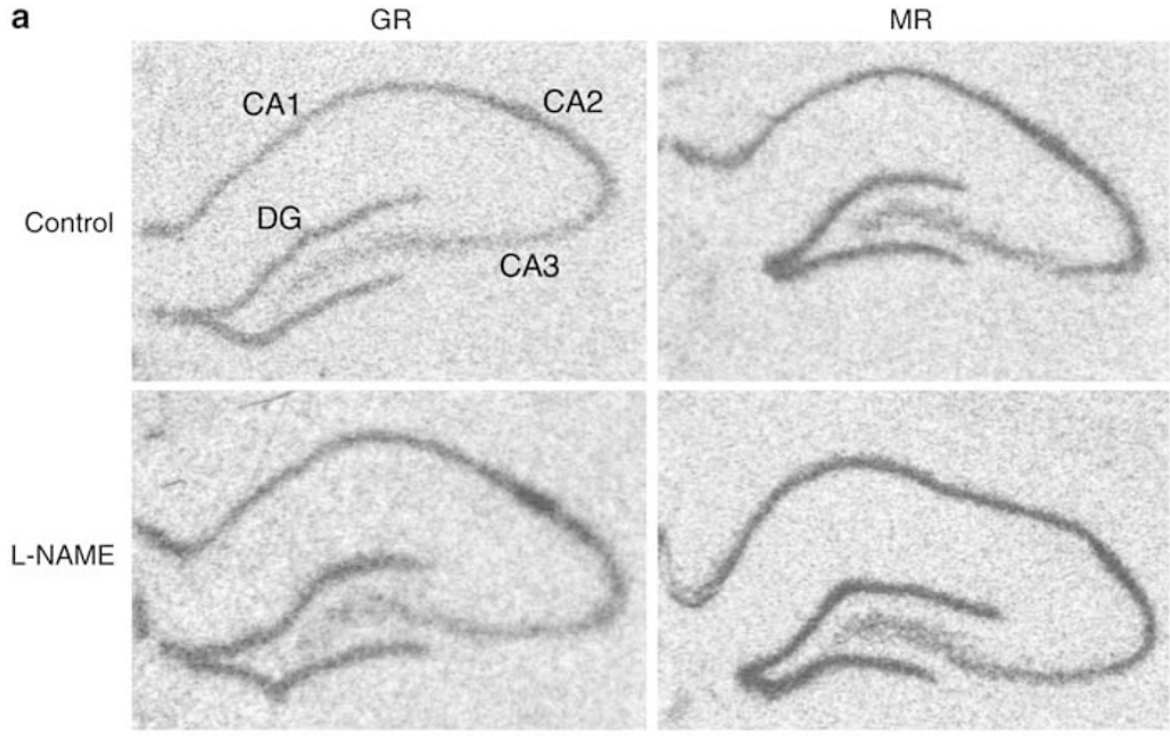

b

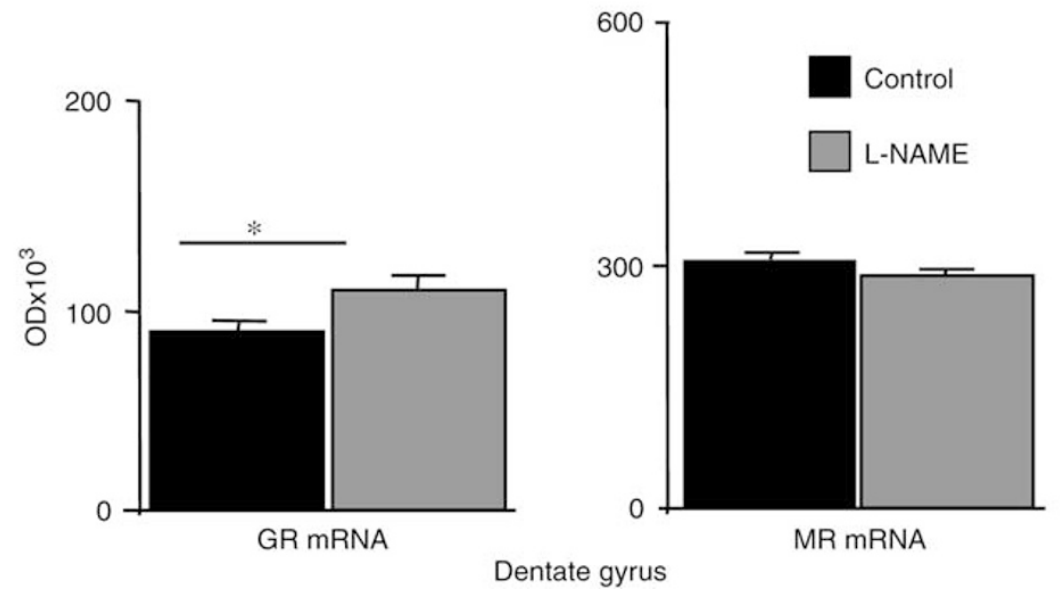

Figure 5 (a) The expression of GR and MR mRNA in the dentate gyrus. (b) Expression of either receptor mRNA following treatment with L-NAME $(50 \mathrm{mg} / \mathrm{kg} /$ day $)$ for 7 days. Values: means \pm SEM. $* p<0.05$.

\section{DISCUSSION}

We used two markers of progenitor proliferation in the adult dentate gyrus in the first experiment: BrdU and Ki-67. There have been suggestions that the former may be toxic to dividing cells (Caldwell et al, 2005), but we find that there is a high correlation between this marker and Ki-67. Experiments 2 and 3 therefore relied on Ki-67 labelling alone to detect dividing progenitor cells.

The first set of experiments showed that, as expected, L-NAME stimulated proliferation rates in intact rats (Cheng et al, 2003; Moreno-Lopez et al, 2004; Packer et al, 2003; Park, 2003). Additional daily corticosterone injections (at a relatively high dose) reduced the number of proliferating cells (also as expected), but L-NAME still was able to increase the number dividing cells in the dentate gyrus even in the presence of excess glucocorticoid, albeit from a much lower baseline. This suggests that excess corticosterone does not inhibit sensitivity to L-NAME.

The second experiment also revealed that proliferation in the dentate gyrus is exquisitely sensitive to corticoids. There is a circadian pattern in progenitor activity: proliferation rates were lower at the beginning of the dark (activity) phase than towards its end. This rhythm tracks that in plasma corticosterone, but is abolished in intact rats implanted with a pellet of corticosterone, a treatment that maintained approximately baseline levels of this steroid but without the normal diurnal rhythm. This shows that the rhythm in progenitor cell activity in adult rats is driven by corticosterone. However, a recent paper failed to find a diurnal rhythm in Ki-67- or BrdU-labelled cells in mice (van der Borght et al, 2006). One important point, however, is that this study used 12-week-old mice (as opposed to our 8-week-old rats); as the authors of this paper themselves concede, levels of neurogenesis have dropped significantly between week 8 and 12. It could be that this age-related decline in neurogenesis (Heine et al, 2004) means that a rhythm of proliferation that is detectable at 8 weeks is no longer detectable at 12 weeks. There may, of course, also be a species difference. In a study comparing the progenitor granule cells derived from mouse and rat brain, Ray and Gage (2006) discovered major differences between the proliferation of these cells in response to a variety of common substrates and mitogenic and differentiation 

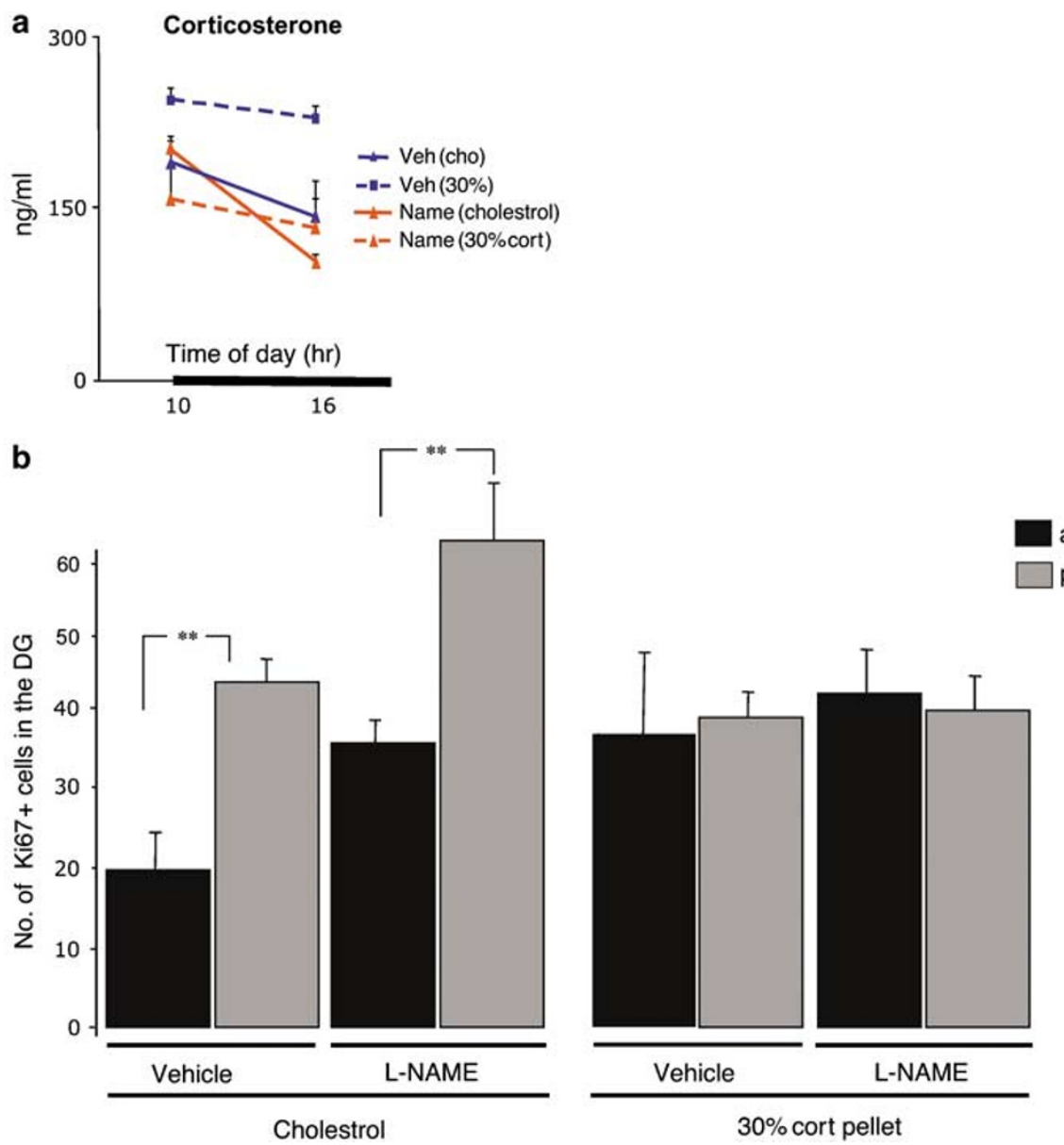

Figure 6 (a) Plasma corticosterone levels at 1000 (peak light off) and $1600 \mathrm{~h}$ in intact rats implanted with either one cholesterol or $30 \%$ corticosterone pellets 7 days after being given either vehicle or L-NAME. (b) Number of Ki-67-positive cells following L-NAME or vehicle treatment for 7 days in the same rats. Values: means \pm SEM. $* * * p<0.001$.

factors. Ambrogini et al (2002) examined diurnal changes in proliferation using BrdU. BrdU incorporates into DNA in the $S$ phase of the cell cycle and is available for at least $2 \mathrm{~h}$ after a single injection. Plasma corticosterone concentrations are likely to change over this $2 \mathrm{~h}$ period. This may lead to significant changes in the level of proliferation even within this time frame. It is more appropriate to assess short-term changes in proliferation rates using Ki-67 which labels dividing cells at exactly the point the animal is killed. In addition, although $\mathrm{Ki}-67$ and BrdU IHC in the dentate gyrus is correlated, a single injection of BrdU consistently labels less cells that Ki-67, most likely because it only labels cells in the $S$ phase. Hence, any diurnal changes in proliferation may be less evident if only a proportion of the dividing cells are labelled. The striking result from our experiment is that the progenitors' response to L-NAME was abolished in the absence of a daily rhythm in corticosterone. It appears that either the drug itself requires a circadian rhythm in glucocorticoids to be effective, or that the mechanism regulating progenitor cells activity becomes insensitive to changes in NO in the absence of a corticoid rhythm. This result recalls our earlier finding that fluoxetine also becomes ineffective in stimulating neurogenesis in the dentate gyrus if the daily corticosterone rhythm is flattened (Huang and Herbert, 2006).
Why are changes in $\mathrm{NO}$ and 5HT, two major factors controlling progenitor cell proliferation, ineffective in animals in which the diurnal rhythm in corticosterone has been attenuated? There are several possibilities, none of which has yet been addressed. Diurnal rhythms in glucocorticoids may drive 'slave' cellular rhythms in the hippocampus as in other areas of the body (Hastings et al, 2003). The hippocampus expresses per genes (Shieh, 2003), and it may be these are required for at least some regulatory processes to be effective. Alternatively, the daily rhythm in corticoids may be needed to retain sensitivity to corticoids in the dentate gyrus, and this may be a necessary permissive condition for $\mathrm{NO}$ and 5HT to act. However, the data in this experiment, and that in a previous one (Huang and Herbert, 2005) provide some evidence that NO and 5HT may act downstream of corticoids. It is interesting to note that despite inhibition of NOS with L-NAME in the cholesterol-treated intact group, the circadian increase in proliferation still occurs at 1600 hours compared to 1000 hours. Hence, corticosterone does not require normal levels of NOS activity, and therefore levels of NO, for this circadian increase to occur. This seems to confirm that corticosterone is acting as the main driving force of the diurnal rhythm in proliferation.

Exercise stimulates proliferation, so it might be that corticoids act secondarily on patterns of locomotor activity 

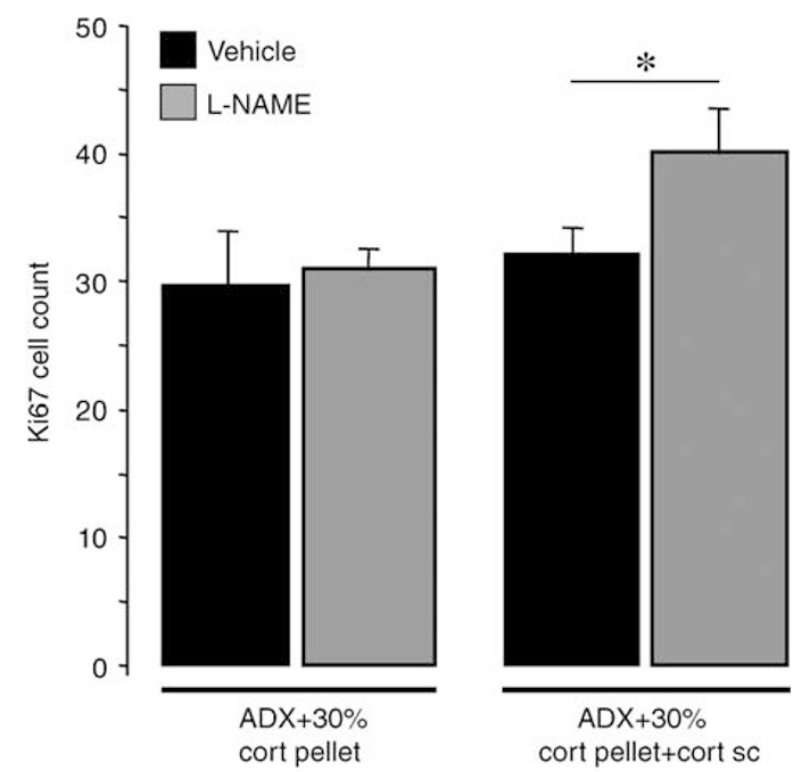

Figure 7 Effect of L-NAME on Ki-67-labeled cell counts in adrenalectomized (ADX) rats implanted with one $30 \%$ s.c. corticosterone pellets and receiving either additional $(2 \mathrm{mg} / \mathrm{kg} /$ day $)$ corticosterone or seasame oil daily at $1000 \mathrm{~h}$ for 12 days. Values: means \pm SEM. $* p<0.03$.

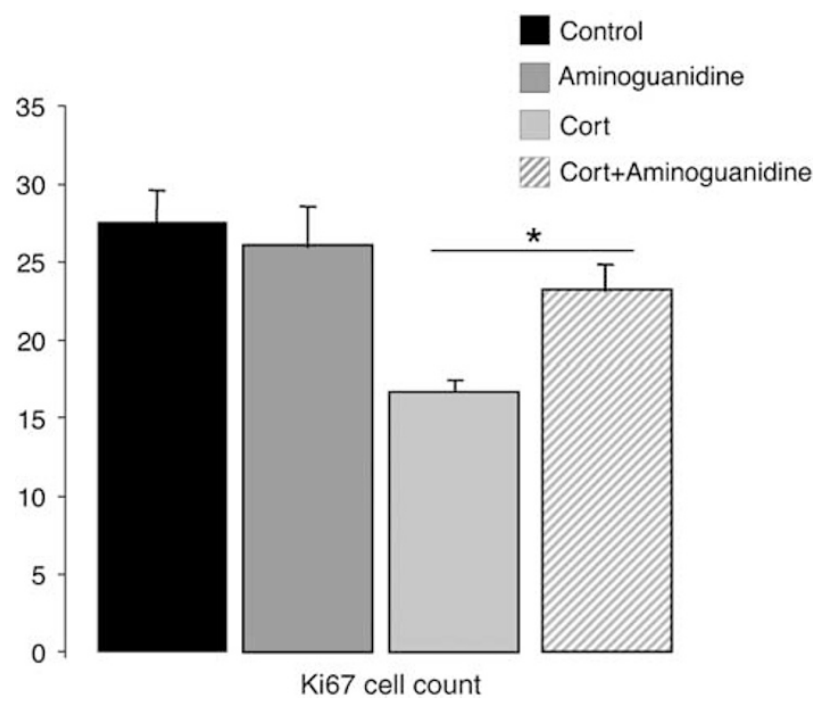

Figure 8 Ki-67 cell count in the dentate gyrus after treatment with either aminoguanidine $(100 \mathrm{mg} / \mathrm{kg})$, or daily corticosterone injection $(40 \mathrm{mg} / \mathrm{kg})$ for 7 days or both. Values: means \pm SEM. $* p<0.03$.

to regulate neurogenesis. However, changing the corticoid rhythm in animals kept under a diurnal lighting regime does not drive activity rhythms (Albers et al, 1985). Whatever the eventual explanation, the findings in this paper may have clinical significance. A substantial proportion (c. 50\%) of patients with major depression also show attenuated or flattened diurnal rhythms in cortisol (Bridges and Jones, 1966; Keller et al, 2006; von Zerssen et al, 1987). Increased neurogenesis in the dentate has been related to the therapeutic response to anti-depressants (Malberg et al, 2000; Santarelli et al, 2003; Sapolsky, 2004), although a recent paper reports no association between Ki-67 labelling and depression in the human dentate gyrus (Reif et al,
2006). If future work substantiates this association, then it may be that manipulation of the adrenal axis might improve the sensitivity of the neurogenetic process to controlling agents and hence the therapeutic response to some antidepressants.

The third experiment was intended to explore the effect of L-NAME in ADX rats with an implanted corticosterone pellet (and hence no diurnal corticoid rhythm) and whether restoring the daily corticoid rhythm (by an additional daily injection of corticosterone) would restore sensitivity to LNAME. L-NAME was not effective in ADX-implanted rats. However, injecting them with $2 \mathrm{mg} / \mathrm{kg} /$ day at the beginning of the dark phase (as in our earlier experiments: (Huang and Herbert, 2006) apparently restored sensitivity of the progenitor cells to L-NAME (as it did to fluoxetine), as there was a significant increase in the number of proliferating cells in this group. It seems clear that a daily rhythm in corticosterone is required for L-NAME to stimulate progenitor cell proliferation.

How does L-NAME alter proliferation rates in the dentate gyrus? The first possibility is that it does so by lowering plasma corticosterone, an event that is well known to increase proliferation. In the first experiment, L-NAME treatment significantly lowered plasma corticosterone, which supports such an interpretation. Reduced expression of GR in L-NAME-treated rats is consistent with this finding. However, the fact that L-NAME was still effective in the presence of excess corticosterone also suggests that this may not be a complete explanation. In the second experiment, also on intact rats, L-NAME had no effect on plasma corticosterone at either time point. We cannot fully account for this difference between the first and second experiment: rats were killed approximately the same time after the same does of the last L-NAME injection. As L-NAME was still effective in spite of unchanged plasma corticosterone, this further argues against lowered plasma levels as the sole explanation of its action. The third experiment, however, opened another possibility: plasma levels were lower in LNAME-treated ADX rats bearing corticosterone implants than in the saline-injected controls. This is reinforced by the finding that L-NAME also lowered plasma corticosterone in intact rats implanted with a corticosterone pellet in the second experiment. This points to an effect of L-NAME on either absorption of the steroid from the implants, or its clearance from the plasma. We have no direct evidence on either of these possibilities. These results do not easily fit those of Givalois et al (2002), who report increased ACTH levels after NOS blockade with two other inhibitors (of eNOS and iNOS) given i.c.v. (rather than i.p.), although they did not measure corticosterone. Earlier, Weidenfeld et al (1999) had found that L-NAME enhanced stress responses but had no effect on basal levels of either ACTH or corticosterone. It is clear that this topic needs further exploration.

Do corticoids depress neurogenesis by stimulating NO formation? The results in this paper suggest that at least one way that glucocorticoids may reduce proliferation is by increasing the expression of iNOS and/or eNOS. iNOS has very low expression in the dentate gyrus of control animals (Liu et al, 2005), but is markedly stimulated by excess corticosterone. Interestingly nNOS, the neural form of NO, was not altered by such treatment, although whether 
withdrawal of glucocorticoids entirely by ADX without replacement (a procedure that stimulates proliferation above baseline values) would change nNOS is still unknown. Flattening the corticosterone rhythm had no effect on iNOS, which suggests that it is sensitive to absolute levels of corticosterone, rather than to the circadian pattern. The fact that L-NAME was still effective in corticosterone-treated rats also suggests that the action of NO is 'downstream' of that of corticosterone. However, as there is no apparent daily variation in either iNOS or nNOS (we did not measure eNOS in this experiment), we have no evidence that the corticoid-dependent daily rhythm in progenitor cell proliferation is driven by NO. The limits of sensitivity of the immunochemical procedure we used make this a cautious conclusion. In the fourth experiment, we tested directly the proposition that iNOS was responsible for the diminished proliferation observed after corticosterone treatment by using the selective iNOS antagonist aminoguanidine. This drug significantly increased the number of labelled proliferating cells in rats receiving additional corticosterone. This strongly supports the notion that iNOS is involved in the suppressive actions of excess gluococorticoids on neurogenesis in the adult dentate gyrus. Interestingly, we were not able to show increased proliferation after aminoguanidiine in control (adrenal-intact) animals. This suggests that iNOS may have a primary role only under conditions of heightened glucocorticoids, a result that fits with our immunohistochemical observations. These showed that iNOS protein was demonstrable only in corticosteronetreated rats, although the in situ readings did suggest a low level of expression of iNOS mRNA in control animals.

The presence of NOS in the dentate gyrus, and the changes we observed after excess corticosterone, suggest that inhibition of one or more isoforms of NOS within the dentate gyrus may thus have a local effect on progenitor proliferation in addition to those consequent upon changes in plasma corticosterone. We attempted to determine whether this was likely to be a direct action on the progenitor cells themselves, or on surrounding cells, by seeing if BrdU and NOS labelling could be localized to the same cell. The results for nNOS were distinct: dividing progenitor cells do not express nNOS, so if this isoform is, indeed, implicated in the regulation of their activity, it seems to be through actions on surrounding cells in the neurogenetic 'niche'. Our attempts to do the same for iNOS were impeded by the low expression of this isoform in control rats, and by the fact that, in those in which it was stimulated by excess corticosterone, BrdU labelling was much reduced. However, we found only two cells that were labelled for both BrdU and iNOS, but more that were labelled for one or the other. This suggests, but does not prove, that both iNOS or nNOS may have indirect actions on the progenitor cells of the dentate gyrus. Further investigation of eNOS, which is more widely distributed in the dentate gyrus, is required.

The mechanism whereby lowered NOS stimulates neurogenesis is still unclear. NO has a wide range of actions on downstream genes (Hemish et al, 2003). Other possibilities include inhibiting the enzyme ribonucleotide reductase which is responsible for synthesizing the deoxyribonucleotides required by dividing cells to replicate their DNA (Kwon et al, 1991). Changing the activities of growth factors is one possibility. Intracerebral infusions of brain-derived neurotropic factor (BDNF) simulate neurogenesis (Pencea et al, 2001; Scharfman et al, 2005). However, the literature relating $\mathrm{NO}$ and BDNF is still inconclusive. Cheng et al (2003) reported that blockade of NOS prevented the effects of BDNF on cortical neurogenesis in culture. Chen et al (2006) found that L-NAME blocked the exercise-induced increase in BDNF in the hippocampus. These results are not consistent with the idea that inhibiting NOS increases BDNF and thus stimulates proliferation of progenitor cells. In our hands, L-NAME increases BDNF in the dentate gyrus (unpublished data). It is well established that NO can activate guanylyl cyclase, but there is evidence that this may not be implicated in the neurogenetic action of reduced NO (Canals et al, 2001; Magalhaes et al, 2006). NO-induced cell death has been prevented in a neural progenitor cell line by inhibiting the MAP kinase protein p38 (Cheng et al, 2001). The role of iNOS in the control of the progenitor cells in the dentate gyrus remains to be explored further. In particular, NO has actions on a variety of other neuroactive substances (eg interleukins) which may contribute to the regulation of dentate progenitor cells (Gadek-Michalska and Bujajski, 2005; Kaneko et al, 2006).

So far as we know, this paper is the first to explore the interaction between two major controlling agents of neurogenesis, NO and glucocorticoids. The stimulating action of inhibiting NOS seems to depend on the presence of rhythmic changes in plasma corticosterone. Excess glucocorticoids given in a periodic fashion (ie by daily injection) do not alter the response to L-NAME, even though proliferation rates are drastically reduced by the corticoid treatment. The effects of reduced NO on neurogenesis may rely on a dual mechanism: corresponding reductions in plasma corticosterone and increased induction of iNOS within the dentate gyrus, although this proposition needs further support. The possibility that NO acts downstream of glucocorticoids in the dentate gyrus is suggested, but not proven, by the experiments reported here, and also warrants further study.

\section{ACKNOWLEDGEMENTS}

This work was supported by a grant from the Wellcome Trust. We thank Helen Shiers for the corticosterone assays. $\mathrm{RB}, \mathrm{MC}$, LTH, and TT-S were undergraduate members of the laboratory during their third-year research projects. $\mathrm{Z}$ Bandpey carried out an initial exploratory experiment and Adrian Newman helped with the figures.

\section{REFERENCES}

Albers HE, Yogev L, Todd RB, Goldman BD (1985). Adrenal corticoids in hamsters: role in circadian timing. Am J Physiol 248: R434-R438.

Altman J, Das GD (1965). Autoradiographic and histological evidence of postnatal hippocampal neurogenesis in rats. J Comp Neurol 124: 319-335.

Ambrogini P, Orsini L, Mancini C, Ferri P, Barbanti I, Cuppini R (2002). Persistently high corticosterone levels but not normal circadian fluctuations of the hormone affect cell proliferation in the adult rat dentate gyrus. Neuroendocrinology 76: 366-372. 
Bridges PK, Jones MT (1966). The diurnal rhythm of plasma cortisol concentration in depression. Br J Psychiatry 112: 1257-1261.

Caldwell MA, He X, Svendsen CN (2005). 5-Bromo-2'-deoxyuridine is selectively toxic to neuronal precursors in vitro. Eur J Neurosci 22: $2965-2970$

Cameron HA, Gould E (1994). Adult neurogenesis is regulated by adrenal steroids in the dentate gyrus. Neuroscience 61: 203-209.

Canals S, Casarejos MJ, Rodriguez-Martin E, de Bernardo S, Mena MA (2001). Neurotrophic and neurotoxic effects of nitric oxide on fetal midbrain cultures. J Neurochem 76: 56-68.

Cardenas A, Moro MA, Hurtado O, Leza JC, Lizasoain I (2005). Dual role of nitric oxide in adult neurogenesis. Brain Res Rev 50: 1-6.

Chen MJ, Ivy AS, Russo-Neustadt AA (2006). Nitric oxide synthesis is required for exercise-induced increases in hippocampal BDNF and phosphatidylinositol $3^{\prime}$ kinase expression. Brain Res Bull 68: 257-268.

Chen X, Herbert J (1995). Regional changes in c-fos expression in the basal forebrain and brainstem during adaptation to repeated stress: Correlations with cardiovascular, hypothermic and endocrine responses. Neuroscience 64: 675-685.

Cheng A, Chan SL, Milhavet O, Wang S, Mattson MP (2001). p38 MAP kinase mediates nitric oxide-induced apoptosis of neural progenitor cells. J Biol Chem 276: 43320-43327.

Cheng A, Wang S, Cai J, Rao MS, Mattson MP (2003). Nitric oxide acts in a positive feedback loop with BDNF to regulate neural progenitor cell proliferation and differentiation in the mammalian brain. Dev Biol 258: 319-333.

Christie BR, Cameron HA (2006). Neurogenesis in the adult hippocampus. Hippocampus 6: 199-207.

Dallman MF, Akana SF, Strack AM, Scribner KS, Pecoraro N, La Fleur SE et al (2004). Chronic stress-induced effects of corticosterone on brain: direct and indirect. Ann NY Acad Sci 1018: $141-150$.

Fish EW, Shahrokh D, Bagot R, Caldji C, Bredy T, Szyf M et al (2004). Epigenetic programming of stress responses through variations in maternal care. Ann NY Acad Sci 1036: 167-180.

Gadek-Michalska A, Bujajski J (2005). Nitric oxide mediates the interleukin-1-beta and nicotine-induced hypothalamic-pituitaryadrenocortical response to social stress. J Physiol Pharmacol 56: 491-503.

Givalois L, Songyun LI, Pelletier G (2002). Central nitric oxide regulation of the hypothalamic-pituitary-adrenocortical axis in adult male rats. Mol Brain Res 102: 1-8.

Hastings MH, Reddy AB, Maywood ES (2003). A clockwork web: circadian timing in brain and periphery, in health and disease. Nat Rev Neurosci 4: 649-661.

Hastings NB, Gould E (1999). Rapid extension of axons into the CA3 region by adult-generated granule cells. J Comp Neurol 413: 146-154.

Heine VM, Maslam S, Joels M, Lucassen PJ (2004). Prominent decline of newborn cell proliferation, differentiation, and apoptosis in the aging dentate gyrus, in absence of an agerelated hypothalamus-pituitary-adrenal axis activation. Neurobiol Aging 25: 361-375.

Hemish J, Nakaya N, Mittal V, Enikolopov G (2003). Nitric oxide activates diverse signaling pathways to regulate gene expression. J Biol Chem 278: 42321-42329.

Huang GJ, Herbert J (2005). The role of 5-HT1A receptors in the proliferation and survival of progenitor cells in the dentate gyrus of the adult hippocampus and their regulation by corticoids. Neuroscience 135: 803-813.

Huang GJ, Herbert J (2006). Stimulation of neurogenesis in the hippocampus of the adult rat by fluoxetine requires rhythmic change in corticosterone. Biol Psychiatry 59: 619-624.

Islam AT, Kuraoka A, Kawabuchi M (2003). Morphological basis of nitric oxide production and its correlation with the polysialylated precursor cells in the dentate gyrus of the adult guinea pig hippocampus. Anat Sci Int 78: 98-103.
Kaneko N, Kudo K, Mabuchi T, Takemoto K, Fujimaki K, Wati H et al (2006). Suppression of cell proliferation by interferon-alpha through interleukin-1 production in adult rat dentate gyrus. Neuropsychopharmacology (in press).

Kee N, Sivalingam S, Boosntra R, Wojtowicz JM (2002). The utility of KI-67 and BrdU as proliferative markers of adult neurogenesis. J Neurosci Methods 115: 97-105.

Keller J, Flores B, Gomez RG, Solvason HB, Kenna H, Williams GH et al (2006). Cortisol circadian rhythm alterations in psychotic major depression. Biol Psychiatry 60: 472-478.

Kwak EK, Kim JW, Kang KS, Lee YH, Hua QH, Park TI et al (2005). The role of inducible nitric oxide synthase following spinal cord injury in rat. J Korean Med Sci 20: 663-669.

Kwon NS, Stuehr DJ, Nathan CF (1991). Inhibition of tumor cell ribonucleotide reductase by macrophage-derived nitric oxide. J Exp Med 174: 761-767.

Liu P, Smith PF, Appleton I, Darlington CL, Bilkey DK (2005). Hippocampal nitric oxide synthase and arginase and ageassociated behavioral deficits. Hippocampus 15: 642-655.

Magalhaes CR, Socodato RE, Paes-de-Carvalho R (2006). Nitric oxide regulates the proliferation of chick embryo retina cells by a cyclic GMP-independent mechanism. Int J Dev Neurosci 24: 53-60.

Malberg JE, Eisch AJ, Nestler EJ, Duman RS (2000). Chronic antidepressant treatment increases neurogenesis in adult rat hippocampus. J Neurosci 20: 9104-9110.

McQuade RLM, Gartside SE, Young AH (2004). Effect of chronic lithium treatment on glucocorticoid and 5-HT1A receptor messenger RNA in hippocampal and dorsal raphe nucleus regions of the rat brain. J Psychopharmacol 18: 496-501.

Meaney MJ, Diorio J, Francis D, Widdowson J, LaPlante P, Caldji C et al (1996). Early environmental regulation of forebrain glucocorticoid receptor gene expression: implications for adrenocortical responses to stress. Dev Neurosci 18: 49-72.

Mineta K, Nomura M, Terado M, Fujimoto N, Sasaguri T, Ueta Y et al (2004). Upregulation of corticotropin-releasing hormone gene expression in the paraventricular nucleus of cyclophosphamide-induced cystitis in male rats. Brain Res 1018: 193-200.

Mirescu C, Gould E (2006). Stress and adult neurogenesis. Hippocampus 16: 233-238.

Mirescu C, Peters JD, Gould E (2004). Early life experience alters response of adult neurogenesis to stress. Nat Neurosci 7: 841-846.

Moreno-Lopez B, Romero-Grimaldi C, Noval JA, Murillo-Carretero M, Matarredona ER, Estrada C (2004). Nitric oxide is a physiological inhibitor of neurogenesis in the adult mouse subventricular zone and olfactory bulb. J Neurosci 24: 85-95.

Packer MA, Stasiv Y, Benraiss A, Chmielnicki E, Grinberg A, Westphal $\mathrm{H}$ et al (2003). Nitric oxide negatively regulates mammalian adult neurogenesis. Proc Natl Acad Sci USA 100: 9566-9571.

Park C (2003). The chronic inhibition of nitric oxide synthase enhances cell proliferation in the adult rat hippocampus. Neurosci Lett 339: 9-12.

Pencea V, Bingaman KD, Wiegand SJ, Luskin MB (2001). Infusion of brain-derived neurotrophic factor into the lateral ventricle of the adult rat leads to new neurons in the parenchyma of the striatum, septum, thalamus, and hypothalamus. J Neurosci 21: 6706-6717.

Ray J, Gage FH (2006). Differential properties of adult rat and mouse brain-derived neural stem/progenitor cells. Mol Cell Neurosci 31: 560-573.

Reif A, Fritzen S, Finger M, Strobel A, Lauer M, Schmitt A et al (2006). Neural stem cell proliferation is decreased in schizophrenia, but not in depression. Mol Psychiatry 11: 514-522.

Santarelli L, Saxe M, Gross C, Surget A, Battaglia F, Dulawa S et al (2003). Requirement of hippocampal neurogenesis for the behavioral effects of antidepressants. Science 301: 805-809. 
Sapolsky R, Armanini M, Packan D, Tombaugh G (1987). Stress and glucocorticoids in aging. Endocrinol Metab Clin North Am 16: 965-980.

Sapolsky RM (2004). Is impaired neurogenesis relevant to the affective symptoms of depression? Biol Psychiatry 56: 137-139.

Scharfman H, Goodman J, Macleod A, Phani S, Antonelli C, Croll S (2005). Increased neurogenesis and the ectopic granule cells after intrahippocampal BDNF infusion in adult rats. Exp Neurol 192: 348-356.

Shieh KR (2003). Distribution of the rhythm-related genes rPERIOD1, rPERIOD2, and rCLOCK, in the rat brain. Neuroscience 118: 831-843.

van der Borght K, Ferrari F, Klauke K, Roman V, Havekes R, Sgoifo A et al (2006). Hippocampal cell proliferation across the day: increase by running wheel activity, but no effect of sleep and wakefulness. Behav Brain Res 167: 36-41.

van Riel EMO, Steenbergen PJ, Joels M (2003). Chronic unpredictable stress causes attenuation of serotonin responses in cornu ammonis 1 pyramidal neurons. Neuroscience 120: 649-658. von Zerssen D, Doerr P, Emrich HM, Lund R, Pirke KM (1987). Diurnal variation of mood and the cortisol rhythm in depression and normal states of mind. Eur Arch Psychiatry Neurol Sci 237: 36-45.

Weaver SA, Aherne FX, Meaney MJ, Schaefer AL, Dixon WT (2000). Neonatal handling permanently alters hypothalamicpituitary-adrenal axis function, behaviour, and body weight in boars. J Endocrinol 164: 349-359.

Weidenfeld J, Feldman S, DeKeyser FG, Ovadia H (1999). Effect of exogenous nitric oxide and inhibitors of nitric oxide synthase on the hypthalamic pituitary adrenal axis responses to neural stimuli. Neuroendocrinology 70: 153-159.

Wong EY, Herbert J (2004). The corticoid environment: a determining factor for neural progenitors' survival in the adult hippocampus. Eur J Neurosci 20: 2491-2498.

Wong EY, Herbert J (2006). Raised circulating corticosterone inhibits neuronal differentiation of progenitor cells in the adult hippocampus. Neuroscience 137: 83-92. 